\title{
Strategic planning: how one successful farmer organises and plans his farming business
}

D.A. NEAL

Taki Taki, Whangaehu, R.D. 6, Masterton

\begin{abstract}
Management-driven farming requires planning as its essential ingredient. This paper elucidates the planning systems that one Wairarapa farmer uses to control and increase the performance of his business. Planning from long term through to day to day is examined relative to actual goals and visions. Relevant business philosophies as well as information inputs are included.
\end{abstract}

Keywords: control, goals, information, management, planning, vision

Time dedicated to planning and organisation in my business is an investment with high return. It clarifies thoughts, creates opportunities, reduces stress and changes reactive farming into proactive farming.

Along with my wife Elsje and two children I farm three units in northern Wairarapa. 424 ha of leased land adjoin 106 ha purchased in 1988. This 530 ha block, 27 $\mathrm{km}$ north of Masterton is all medium to steep summer dry hill country. This was complemented by the purchase of $242 \mathrm{ha}, 1 \mathrm{~km}$ north of Eketahuna in 1991. This farm includes 100 ha of flat land in a good summer rainfall dairying area.

Wintered stock this year include 325 rising 1-year bulls, 2550 hoggets, 4850 ewes and 45 rams. Farming policy has included grazing Friesian bulls on hill country for 10 years for high cash return, continued improvement of capital stock performance and land and pasture development. My system must be simple and flexible.

\section{Vision and goals}

Organising and planning my farming business is a structured and strategic activity. To formulate a plan I need a vision of the future and goals. These are created and shaped by both my personality and the environment I work in. Firstly is the "wish list" which is tempered and tuned by personal factors such as family, perceived opportunities and the changing economics of farming. Putting these goals to paper is important to the planning process to clarify thought and also allow retrospective checks on progress. These goals are given considerable thought and written out in detail.
An example of one long-term business goal is accumulation of 1200 ha of medium to good quality hill country with some flat and easier finishing country, plus 150 ha of dairy farm.

\section{One- to five-year planning}

A combination of long-term goals and my business philosophies dictate my one- to five-year plan.

My current plan includes:

1. Large repayment of debt

2. Attaining stock performancew above a minimum of $6 \mathrm{~kg}$ wool per sheep stock unit, 120\% lambing, $230 \mathrm{~kg}$ carcass weight in March for 19-month bulls. 3. Increasing bull numbers to 400 .

4. Substituting 40 breeding cows for sheep.

5. Renovating 30 ha of pasture each year for 3 years.

6. Applying 600 tons of lime to the Eketahuna block.

7. A major improvement to an access impediment.

\section{Within-year planning}

\section{(a) Financial}

Objectives from the five-year plan are grafted into the one-year plan with two or three main goals being incorporated. The formal part of the one year plan usually occurs in March preceding the July to June financial year. This plan involves a stock policy and development policy for that year. This is transferred to stock reconciliations and a cash flow budget. The mechanics of this process are quick and simple. However, it is important to spend time considering other options and refinements. This often necessitates partial budgeting and rebudgeting, till I am satisfied that the plan is efficient and attains its goals.

Full budget reviews with necessary alterations occur in June, October, February and if special events occur. All financial transactions are coded on the bank statement, using accountant's numbering, then transferred to a 12-month ledger set up on the format of my accounts. This allows continual monitoring against the budget. The data are regularly further processed to estimate tax implications, so that this can be manipulated in advance to best advantage. Taxation calculations are simple but important because tax often has major cash flow effects. 
Day to day cash flow management involves entering all transactions into a cash book. Close control and manipulation of cash flow optimises opportunity to invest short-term surplus to advantage, as well as minimising overdraft fees. At least once a month I liase with my bank manager on the current situation and my requirements. Frequent communication eliminates almost all problems.

All income flows are written into the appointment diary on prompt dates and checked with the bank on the following day. All expenses are recorded, on mail opening, under due date in the appointment diary.

\section{(b) Physical}

\section{Livestock}

The stock reconciliation is in itself the key plan, but notes are written describing stock selling methods and target liveweights to achieve at certain times. The benefit of the plan is to focus and clarify thinking, and its value is therefore not diminished if it requires changing as the season develops.

Monitoring the farm situation relative to the plan is essential, for example, stock live weights and stock number on the farm month by month. Sample liveweights are graphed over the same class of livestock from previous years.

\section{Feed budgeting}

Method emphasises simplicity and workability. Stock grazing and movements are drawn out on A4 sketch maps of the farm. In summer, for example, areas required for specialist cattle wintering, hogget areas for September and ewe set stock lambing areas are calculated and labelled. This allows target preparation of those areas in January-February, and monitoring of their feed covers through summer-autumn relative to expected requirements.

A series of 'recipes' have been developed from previous years' experiences on area allocation per animal in different months and required feed cover levels at certain dates. Feed cover over the whole farm is visually assessed at the beginning of March, April and May to compare with previous years and this is balanced against stock numbers and classes being farmed.

The winter feed budgeting for the ewes is calculated as hectares per day for each different mob. I plan the expected requirements and monitor progress weekly to see if it is being achieved. The condition and liveweight of the stock is the final and absolute monitor.

Feed planning is an all year activity, not just autumnwinter. Planning and monitoring is especially important from November to January in a system which produces high pasture growth rates, yet has no breeding cows to later tidy up loose management.

\section{Development}

The development to be achieved within the year is planned in advance, with maps where appropriate and breakdown into machinery, personnel and material requirements. Ordering materials and booking personnel and machinery in advance improves the likelihood of achievement by required dates. This is particularly important for heavy machinery in busy seasons.

\section{Day by day planning}

Planning is especially important with a low labour ratio and two farms $28 \mathrm{~km}$ apart run as one operation. In the middle of each week I assess the following week, lay out dates and priorities. Continuous use is made of the appointment diary.

Each night I prepare a list of the following day's work, telephone calls, appointments and materials required. This is prioritised, timetabled and usually prepared on A4 farm sketch maps. Use of maps improves time in motion efficiency with stock and personnel movements. A copy of this is made and given to staff each day to keep them informed and to avoid confusion.

Notes are kept during the day of stock movements, tallies and jobs identified as needing attention. These jobs are transferred at home to lists according to type, for example, fencing, and these lists are referred to frequently during planning.

\section{Essential input to planning}

\section{(a) Sourcing and adapting information}

Fundamental to planning is a quality flow of relevant information. The information required for the multifaceted farm planning process must be specific yet diverse and up to date. Frequent use is made of a network of contacts with specialist skills. Usually a time saving and improvement in quality of information comes from directly tapping these sources.

Information on new technology is important, but perhaps more important is seeking out relevant information already in existence. My farming system is always changing and continuously requires moreoutside information. For example, the purchasing of flat land required emphasis on pasture renovation skills.

Information sources used in the planning process include:

1. Agletter tipsheets - weekly publications with market reports and topical management features. 
2. Wai Knotz Group - high powered and focused discussion group structure containing selected and capable farmer businessmen from throughout the Wairarapa.

3. Farm consultants.

4. Farming publications.

5. Other farmers.

6. Direct contact with manufacturers and merchants.

7. Newspapers.

\section{(b) Information on the wider scene}

Influential to all the planning process is my perception of the wider scene. To concentrate entirely on the details of within-farm planning can be short-sighted and counter-productive without continual reference to the wider economy both nationally and internationally.

Reading of newspapers, business reviews, specialist publications and attendance at seminars such as Infometrics supplements information from personal contacts. This sort of information allows me to make my own judgements independently on various factors, for example, beef prices and interest rates. It is critical to position my business correctly to take advantage of various trends, particularly with my counter cyclical philosophy. A cyclic downturn needs to be differentiated from a permanent decline and timing is all important.

Monitoring of the wider scene is necessary to check that my business philosophies are still relevant and incisive. These business philosophies permeate through my planning process. For example, my philosophy of above-average stocking rate and above-average per head performance combined with a low cost structure to generate high net returns may need alteration with time.

Farming is a business and many of the principles and methods used in the wider business scene can be advantageously adapted to farming.

Being able to distance oneself mentally from the farm gives perspective to the operation, quantifies problems and allows identification of opportunities. Holidays are an investment in this process, as is time spent touring the operation doing little except thinking. 